\title{
A NEW SIMPLIFIED MODEL FOR PREDICTING THE UV-PROTECTIVE PROPERTIES OF MONOFILAMENT PET FABRICS
}

\author{
Klara Kostajnšek, Raša Urbas, Krste Dimitrovski \\ Faculty for Natural Sciences and Engineering, Department of Textiles, Graphic Arts and Design, University of Ljubljana, Aškerčeva 12, 1000 Ljubljana, \\ Slovenia, Telephone: +386 12003200 \\ E-mail: klara.kostajnsek@ntf.uni-lj.si
}

\begin{abstract}
:
Knowing the reflection, transmission, and absorption properties of the yarns from which the woven fabric is made, prediction of a fabric's UV-protective properties is simple. Using the geometrical properties of monofilament yarns and fabrics, which were determined optically, and following the cover factor theory, we have determined the areas of fabrics covered with no yarns, only one yarn, and two yarns. From a special selected set of highmodule polyethylene terephthalate (PET) monofilament materials (e.g., fabrics), we have elaborated a method for determining the reflection, transmission, and absorption of yarns. By first defining the differently covered areas of fabrics, we were able to use them in a mathematical model for calculating and predicting the UV-protective properties of the fabrics. The calculated and measured values of the UV-protective properties of the selected test fabrics were highly correlated, with a correlation coefficient $>0.98$.
\end{abstract}

\section{Keywords:}

PET monofilament, yarns, fabrics, UV-protective properties, model, prediction of UV-protective properties

\section{Introduction}

In recent decades, protection against the harmful radiation of ultraviolet rays (UV) is becoming increasingly important because of the depletion of the ozone layer in the atmosphere. Despite certain positive effects of the UV radiation, excessive exposure to the sun has negative effects on people's health, the level of which depends on the quantity of exposure to individual types of UV radiation (UVA, UVB, and/or UVC). Nowadays, preventive actions for the protection of people from the effects of UV are well known, such as setting a daily limit for exposure to the sun's rays, use of sunscreens and sunglasses, the use of pharmacological agents, and the use of protective clothing and hats. The most effective metioned approache for the protection of the skin is the usage of mechanical protective products, which physically prevent harm from the negative effects of UV rays. One of the best and most appropriate options are different textile products, which are used both as clothes and as protection devices between the rays and the concerned person in the sense of prevention of penetration (e.g., sun umbrellas, canopies, etc.).

Many researchers have investigated the influence of different factors related to the textile materials used for UV protection. They have investigated the influence of type of material [1, 2], fabric constructions [1, 3-5], colors, and different additives [6-10].

The advantage of textile protective products, in comparison with pharmaceutical products (sunscreens, lotions, protective oils, etc.), is that textile products do not have to be applied directly into/on the skin, by which we avoid many allergic and other chemical skin reactions. The advantage of using textile products (i.e., clothes) is also that it is easy to separate the protected surface of the skin from the unprotected part when we use them [1-3].

The presentation of the research done so far is based on a search conducted in the Web of Science database. The search was done in two sets, namely, general (no restrictions on the search) and then also with a restriction in the Material Science textile category.

The search was set according to the title, abstract, and keywords:

1. UV protection,

2. UV protection by textiles, and

3. UV protection by textile structure.

Statistical processing of data shows that only about $4 \%$ of the research reports in the Web of Science database includes UV protection in the Material Science textile search category (MST) (270 hits out of 7.433). The number of hits for the search words in points 1 and 2 shows the importance and popularity of the topic, and the number of hits for the search words in point 3 (number of hits $\sim 53$, and number of hits for MST category 22) shows that the number of publications on the topic of protection against UV radiation concerning the structure of textiles is relatively low, which points to a proportionately low number of authors dealing with UV protection of woven textiles from the perspective of construction and prediction, which is the purpose of our research. 
One-layered woven fabrics consist of two different parts in their structure, usually described by the open area and the cover factor [1-3]. The extended version of the cover factor theory also presents the area covered by one yarn and the area covered by two yarns in a fabric's structure (Figure 1).

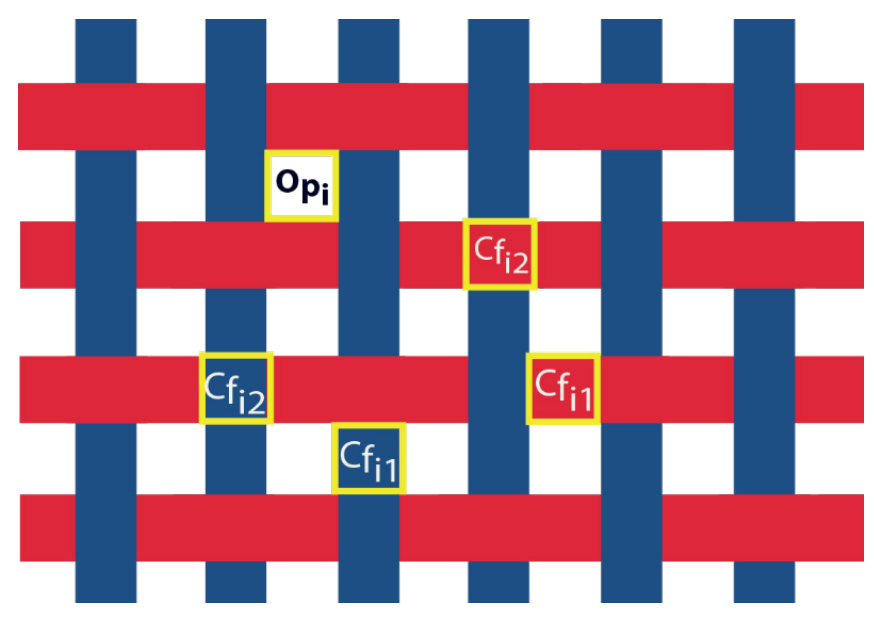

Figure 1. Scheme of woven fabric in plain weave, divided into the areas without yarns - white-colored areas $\left(O p=\Sigma O p_{i}\right)-$ and the areas covered with one $\left(\mathrm{Cf}_{1}=\Sigma C f_{i 1}\right)$ or two yarns $\left(\mathrm{Cf}_{2}=\Sigma C f_{i 2}\right)$, where $\mathrm{i}$ is the number of individual areas in a unit area.

Generally, the theory of the woven fabrics defines the cover factor as a fraction of the surface covered by the yarns. This equals the quotient of the area covered by the yarns divided by the total area of the web construction of the fabric [11], expressed in Equation (1). In this manner, it ranges from the value zero to the value one, and if multiplied by 100 , it can be expressed in percentage.

$$
C f=\text { areacovered by yarns/total area of web }
$$

Calculation of the cover factor consists of calculation of the $\mathrm{Cf}_{\text {wa }}$ (cover factor of warp yarns) and the $\mathrm{Cf}_{\text {we }}$ (cover factor of weft yarns) as follows:

$$
C f_{w a}=D_{w a} \times d_{w e} \text { and } C f_{w e}=D_{w e} \times d_{w e} \text {, }
$$

where $D_{\text {wa }}$ and $D_{\text {we }}$ represent the densities of the warp and the weft, and $d_{w a}$ and $d_{w e}$ denote the diameters of the warp and the weft yarns.

The cover factor of a one-layered fabric is expressed by the cover factor of the warp and the weft yarns. Therefore, Equation (1) can be transformed into Equation (2):

$$
C f=C f_{w a}+C f_{w e}-C f_{w a} \times C f_{w e} .
$$

For the purpose of the research, we had to modify and extend the woven fabric cover factor theory into the next form. The fabric cover factor is a sum of areas covered by one yarn $\left(\mathrm{Cf}_{1}\right)$ and two yarns $\left(\mathrm{Cf}_{2}\right)$, expressed using Equation (3):

$$
C f=C f_{1}+C f_{2} \text {. }
$$

The portion of the fabric covered by two yarns is calculated as follows:

$$
C f_{2}=C f_{w a} \times C f_{w e}
$$

and the portion of the yarns covered by one yarn is derived as follows:

$$
C f_{1}=C f-C f_{2} \text {. }
$$

In one of our previous research works [5], we have evaluated the penetration of UV rays through a one-layered monofilament high-module polyethylene terephthalate (PET) material (e.g., fabrics), in order to determine the amount of reflected, absorbed, and transmitted UV rays by one yarn and two yarns (one on top of the other) in the fabric structure. We have calculated the quotient, as shown in Equations (6-8) for each sample.

$$
\begin{aligned}
& K T_{m}=(T-O p) / C f \text {; } \\
& K R_{m}=R / C f \text {; } \\
& K A_{m}=A / C f
\end{aligned}
$$

where $K T_{m}, K R_{m}$, and $K A_{m}$ represent the coefficients of transmission, reflection, and absorption of the material (e.g., fabric); $T$ and $R$ represent the measured values of transmission and reflection, and $A$ represents the calculated absorption as a difference from 100; Cf represents the cover factor of the woven fabric; and Op represents the open area.

The physical meaning of the quotient represents the amount of transmitted, reflected, and absorbed UV rays by the structure of a certain material (e.g., fabric) in case there is no open area in the sample (e.g., Cf equals 1). Actually, in such supposed cases, the quotients should be equal to the measured values.

\section{Experimental}

\subsection{Materials}

For the purpose of this research, a set of referential material (e.g., fabric) samples, which are used in practice for the production of screen printing meshes, was chosen. The chosen high-module PET meshes (Sefar AGÒ, Inc.) differ in monofilament diameter, warp and weft density, open area portion, fabric thickness, number of pores, and weave. The actual physical and the construction properties, the calculated cover factors, and the values of the open area portions are presented in Table 1. Measurements were obtained with image analyses performed on a scanning electron microscope (SEM).

Table 1 shows why the chosen fabric samples were suitable for the analysis. Samples 1-4 in plane weave differed in the declared warp and weft density $(120,140,150$, and 165 yarns/ $\mathrm{cm}$, respectively), while the monofilament diameter (declared $31 \mu \mathrm{m}$ ) was equal for all the samples (Figure 2).

Samples 5 and 6 were weaved in twill weave and had the same monofilament diameters as the samples 1-4; however, their declared density was higher (180 and 190 yarns/cm) (Figure 
Table 1. All declared and measured values of fabric construction parameters and the calculated cover factors and open area portions

\begin{tabular}{|c|c|c|c|c|c|c|c|c|c|}
\hline \multirow[t]{2}{*}{ Sample } & \multicolumn{2}{|c|}{$\begin{array}{l}\text { Yarn diameter } \\
{[\mu \mathrm{m}]}\end{array}$} & \multicolumn{2}{|c|}{$\begin{array}{c}\text { Warp and weft } \\
\text { density }[y a r n s / c m]\end{array}$} & \multirow{2}{*}{$\begin{array}{c}\begin{array}{c}\text { Number } \\
\text { of pores/ } \\
\mathbf{c m}^{2}\end{array} \\
{ }^{* *} \text { Meas. }\end{array}$} & \multirow{2}{*}{$\begin{array}{c}\begin{array}{c}\text { Fabric } \\
\text { thickness } \\
{[\mu \mathrm{m}]}\end{array} \\
{ }^{* *} \text { Meas. }\end{array}$} & \multirow{2}{*}{$\begin{array}{c}\text { Warp/weft } \\
\text { cover } \\
\text { factor [\%] }\end{array}$} & \multirow{2}{*}{$\begin{array}{c}\begin{array}{c}\text { Fabric } \\
\text { cover } \\
\text { factor } \\
\boldsymbol{C f}_{m} \\
{[\%]}\end{array} \\
{ }^{* *} \text { Meas. }\end{array}$} & \multirow{2}{*}{$\begin{array}{c}\begin{array}{c}\text { Open } \\
\text { area } \\
\text { portion } \\
{[\%]}\end{array} \\
\text { ** Meas }\end{array}$} \\
\hline & ${ }^{*}$ Dec. & **Meas. & ${ }^{*}$ Dec. & **Meas. & & & & & \\
\hline 1 & \multirow{6}{*}{31} & 32.90 & 120 & 123.54 & 15262 & 49 & 40.64 & 64.76 & 35.24 \\
\hline 2 & & 34.25 & 140 & 144.01 & 20738 & 48 & 49.32 & 74.32 & 25.68 \\
\hline 3 & & 35.55 & 150 & 153.82 & 23660 & 47 & 54.68 & 79.46 & 20.54 \\
\hline 4 & & 38.55 & 165 & 162.79 & 26500 & 48 & 62.76 & 86.13 & 13.87 \\
\hline 5 & & 34.20 & 180 & 182.96 & 33474 & 55 & 62.57 & 85.99 & 14.01 \\
\hline 6 & & 35.05 & 190 & 189.90 & 36062 & 55 & 66.56 & 88.82 & 11.18 \\
\hline 7 & 34 & 38.80 & 120 & 122.96 & 15119 & 55 & 47.71 & 72.66 & 27.34 \\
\hline 8 & 40 & 45.50 & 120 & 121.01 & 14643 & 65 & 55.06 & 79.80 & 20.20 \\
\hline
\end{tabular}

Notes: ${ }^{\star}$ Dec. - declared values by producers of the fabrics; ${ }^{*}$ Meas. - measured values.

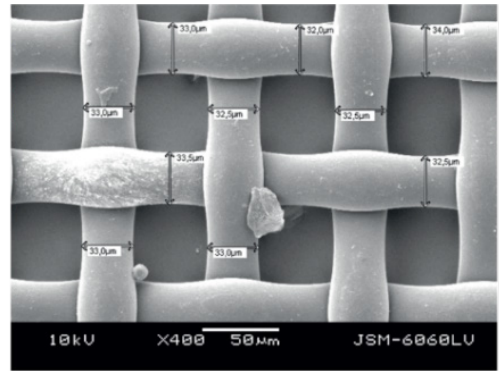

a)

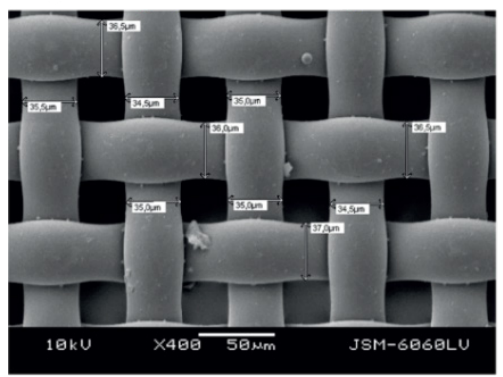

c)

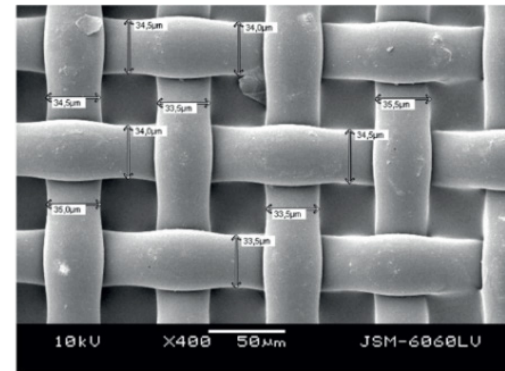

b)

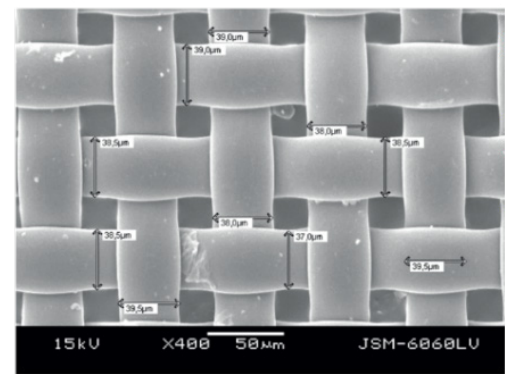

d)

Figure 2. Samples 1 (a), 2 (b), 3 (c), and 4 (d) in plain weave, with equal declared yarn diameter (31 $\mu \mathrm{m})$ and different densities (120, 140, 150, and 165 yarns/cm) $($ SEM; $400 \times$ magnification).

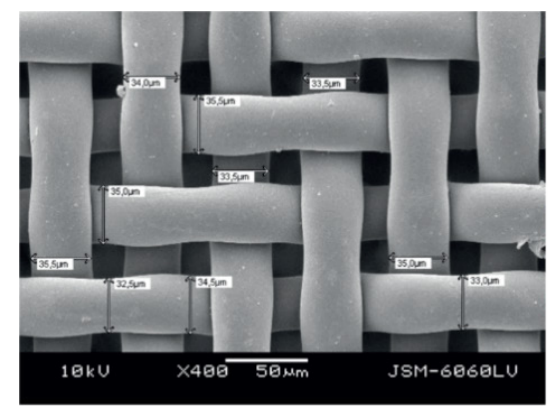

a)

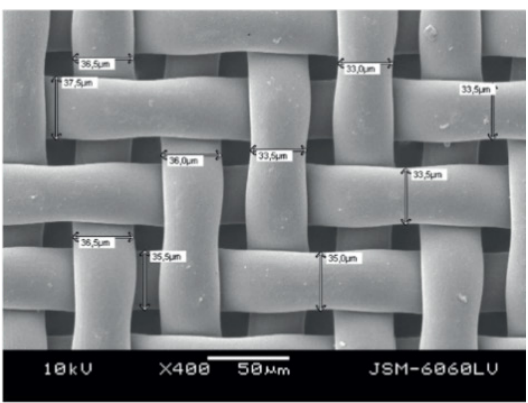

b)

Figure 3. Samples 5 (a) and 6 (b) in twill weave, with equal declared yarn diameter (31 $\mu \mathrm{m})$ and different densities (180 and 190 yarns/cm) (SEM; $400 \times$ magnification). 
3).

Different values of the declared monofilament diameters ( 31 , 34 , and $40 \mu \mathrm{m}$ ) were presented by the samples 1 (a), 7 (b), and 8 (c), which had the same declared warp and weft density (120 yarns/cm) (Figure 4).

\subsection{Methods}

The transmission of the selected samples was measured with Lambda 800 UV-visible spectrophotometer, equipped with PELA-1000 (PerkinEImer, Inc.), which enables measurements of the transmission and the reflection. Measurements were made in accordance with the SIST EN 13758-1 standard, in 2-nm steps, in the range of 700-200 nm. For calculation of the ultraviolet protection factor (UPF), only data within the range 400-290 nm was used.

The average values of the UV transmission $(T)$ were calculated using Equation (9), as follows:

$$
\mathrm{UV}_{\mathrm{i}}=\frac{1}{\mathrm{n}} \sum_{290}^{400} \mathrm{~T}_{\mathrm{i}}(\lambda) \text {. }
$$

The reflection values $(R)$ were calculated in the same manner; however, instead of transmission values, the values of the reflection were inserted into the equation.

The obtained values of the transmission $(T)$ enabled the calculation of the UPF values and, together with the measured values of reflection $(R)$, the absorption $(A)$ can be calculated as shown in Equation (10):

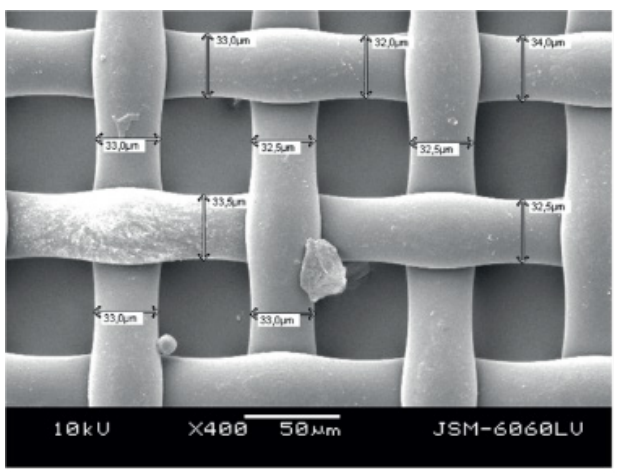

a)

$$
A=100-T-R \text {. }
$$

\section{Results and calculations}

The results of the measured properties are presented in Tables 1-5. Table 2 presents the measured values of the transmission and the reflection, together with the calculated values of absorption, UPF, the portion of the areas covered by one and two yarns, and the constants of transmission, reflection, and absorption. The constants of transmission, reflection, and absorption $\left(K T_{m}, K R_{m}\right.$, and $\left.K A_{m}\right)$ are calculated according to Equations (6-8) and the values of $\mathrm{Cf}$ and $\mathrm{Op}$ are from Table 1.

Using the measured results for $\mathrm{Cf}_{1}$ and $\mathrm{Cf}_{2}$ from Table 2, and combining all possible sample pairs (sample 1 and sample 2, 3 , 4; sample 2 and samples 3 , 4; sample 3 and sample 4 ) in Equation (11) as a system of two equations with two variables [5], we have succeeded in determining the values of $\boldsymbol{K}_{\boldsymbol{l}_{(T, R, A)}}$ and $\boldsymbol{K}_{2_{(T, R, A)}}$ for particular samples.

$$
\mathrm{Cf}_{1} \times \mathrm{K}_{1_{(\mathrm{T}, \mathrm{R}, \mathrm{A})}}+\mathrm{Cf}_{2} \times \mathrm{K}_{2_{(\mathrm{T}, \mathrm{R}, \mathrm{A})}}=\operatorname{measured}(\mathrm{T}, \mathrm{R}, \mathrm{A})
$$

These results are shown in Table 3. For further observation, we took into consideration only samples in plain weave, avoiding the small influence of twill weave on the values of $K_{T}, K_{R}$, and $K_{A}$, as well as on the complexity in their presentation, in tables [5]. On the other hand, conclusions based on the samples in the plain weave were used in the model and showed that the steps are valid for the samples in the twill weave also.

Analysis of the coefficients $K_{1}$ and $K_{2}$ showed that there is

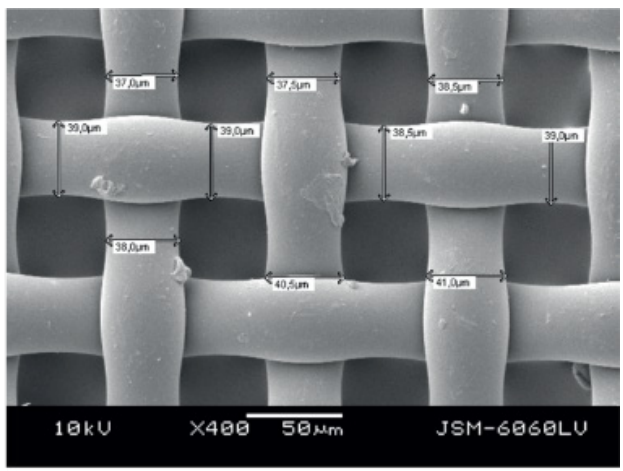

b)

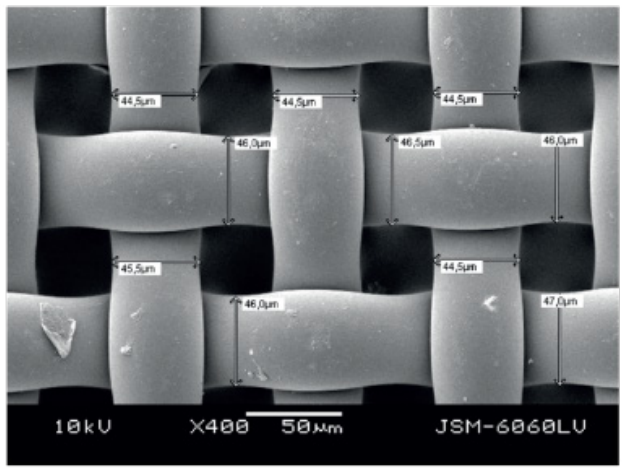

c)

Figure 4. Samples $1(\mathrm{a}), 7$ (b) and 8 (c) in plain weave, with equal declared density (120 yarns/cm) and different yarn diameters (31, 34, and $40 \mu \mathrm{m})(\mathrm{SEM} ; 400 \times$ magnification). 
Table 2. Measured values of the UV transmission $(T)$ and reflection $(R)$, as well as the calculated values of absorption $(\mathrm{A})$ and ultraviolet protection factor (UPF), portion of area covered by one $\left(\mathrm{Cf}_{1}\right)$ and two yarns $\left(\mathrm{Cf}_{2}\right)$, and the calculated constants of transmission, reflection, and absorption $\left(K T_{m}, K R_{m}\right.$, and $\left.K A_{m}\right)$

\begin{tabular}{|c|c|c|c|c|c|c|c|c|c|}
\hline \multirow{2}{*}{ Sample } & $\mathbf{T}[\%]$ & $\mathbf{R}[\%]$ & $\mathbf{A}[\%]$ & $\mathbf{U P F}$ & $\mathbf{C f}_{\mathbf{1}}[\%]$ & $\mathbf{C f}_{\mathbf{2}}[\%]$ & $\mathbf{K T}_{\mathbf{m}}$ & $\mathbf{K R}_{\mathbf{m}}$ & $\mathbf{K A}_{\mathbf{m}}$ \\
\cline { 2 - 11 } & ${ }^{*}$ Meas. & ${ }^{*}$ Meas. & ${ }^{* *}$ Calc. & ${ }^{* *}$ Calc. & ${ }^{* *}$ Calc. & ${ }^{* *}$ Calc. & ${ }^{* *}$ Calc. & ${ }^{* * C a l c .}$ & ${ }^{* *}$ Calc. \\
\hline 1 & 54.22 & 13.72 & 32.06 & 2.37 & 48.24 & 16.52 & 0.293 & 0.212 & 0.495 \\
\hline 2 & 45.95 & 16.17 & 37.88 & 3.08 & 49.99 & 24.33 & 0.273 & 0.218 & 0.510 \\
\hline 3 & 41.76 & 16.53 & 41.71 & 3.71 & 49.56 & 29.90 & 0.267 & 0.208 & 0.525 \\
\hline 4 & 35.83 & 18.12 & 46.05 & 4.84 & 46.75 & 39.38 & 0.255 & 0.210 & 0.535 \\
\hline 5 & 36.02 & 18.68 & 45.30 & 4.78 & 46.84 & 39.15 & 0.256 & 0.217 & 0.527 \\
\hline 6 & 33.01 & 18.81 & 48.18 & 5.79 & 44.52 & 44.30 & 0.246 & 0.212 & 0.542 \\
\hline 7 & 47.02 & 15.44 & 37.54 & 2.92 & 49.90 & 22.76 & 0.271 & 0.212 & 0.517 \\
\hline 8 & 39.25 & 17.36 & 43.39 & 3.87 & 49.48 & 30.32 & 0.239 & 0.218 & 0.544 \\
\hline
\end{tabular}

Notes: ${ }^{\star}$ Meas. - measured values; ${ }^{* *}$ Calc. - calculated values.

Table 3. Calculated values of the transmission $(T)$, reflection $(R)$ and absorption $(A)$ coefficients $K_{1}$ and $K_{2}$ for the Samples $1-4$, 7, and 8 in plain weave

\begin{tabular}{|c|c|c|c|c|c|c|}
\hline Sample & $\mathbf{1 - 4}$ & $\mathbf{1 - 4}$ & $\mathbf{7}$ & $\mathbf{7}$ & $\mathbf{8}$ & $\mathbf{8}$ \\
\hline Sample coefficient & $\mathbf{K}_{\mathbf{1}}$ & $\mathbf{K}_{\mathbf{2}}$ & $\mathbf{K _ { 1 }}$ & $\mathbf{K}_{\mathbf{2}}$ & $\mathbf{K}_{\mathbf{1}}$ & $\mathbf{K}_{\mathbf{2}}$ \\
\hline $\mathrm{T}$ & 0.335 & 0.152 & 0.327 & 0.148 & 0.302 & 0.137 \\
\hline $\mathrm{R}$ & 0.223 & 0.193 & 0.223 & 0.193 & 0.223 & 0.193 \\
\hline $\mathrm{A}$ & 0.442 & 0.654 & 0.450 & 0.662 & 0.460 & 0.680 \\
\hline Sum of coefficients & 1.000 & 0.999 & 1.000 & 1.003 & 0.985 & 1.010 \\
\hline
\end{tabular}

Table 4. Calculated values of transmission $(T)$ coefficients $\left(K_{1 T}, K_{2 T}\right.$, and $\left.K_{1 T}^{2}\right)$, absolute values of differences $\Delta\left(K_{2 T}-K_{1 T}^{2}\right)$, and their connections confirmed with coefficients of correlation

\begin{tabular}{|c|c|c|c|c|}
\hline Sample/Sample coefficient & $\mathbf{K}_{1 \mathrm{~T}}$ & $\mathbf{K}_{2 \mathrm{~T}}$ & $\mathbf{K}_{\mathbf{1 T}}{ }^{2}$ & $\boldsymbol{\Delta}\left(\mathbf{K}_{\mathbf{2 T}}-\mathbf{K}_{\mathbf{1 T}}{ }^{2}\right)$ \\
\hline $1-4$ & 0.335 & 0.152 & 0.1122 & 0.0398 \\
\hline 7 & 0.327 & 0.148 & 0.1069 & 0.0411 \\
\hline 8 & 0.302 & 0.137 & 0.0912 & 0.0458 \\
\hline Correlation coefficient $\mathrm{K}_{2 \mathrm{~T}} ; \mathrm{K}_{1 \mathrm{~T}}{ }^{2}$ & & & 0.9998 & \\
\hline
\end{tabular}

Table 5. Calculated values (from Equation 10) of the absorption coefficients $\left(K_{1 A}, K_{2 A}\right.$, and $\left.\sqrt{K_{1 A}}\right)$, the absolute values of differences $\Delta\left(K_{2 A}-\sqrt{K_{1 A}}\right)$, and their connections confirmed with coefficients of correlation

\begin{tabular}{|c|c|c|c|c|}
\hline \multirow{2}{*}{ Sample } & \multicolumn{3}{|c|}{ Sample coefficient } & $\Delta\left(\mathbf{K}_{2 \mathrm{~A}}-\sqrt{\mathbf{K}_{1 \mathrm{~A}}}\right)$ \\
\hline \multirow{2}{*}{$1-4$} & $\mathbf{K}_{1 \mathrm{~A}}$ & $\mathbf{K}_{2 \mathrm{~A}}$ & $\sqrt{\mathbf{K}_{1 \mathrm{~A}}}$ & \\
\hline & 0.442 & 0.654 & 0.665 & -0.0108 \\
\hline 8 & 0.45 & 0.662 & 0.671 & -0.0088 \\
\hline $\begin{array}{c}\text { Correlation coefficient } \\
\mathrm{K}_{2 \mathrm{~A}} ; \sqrt{\mathrm{K}_{1 \mathrm{~A}}}\end{array}$ & 0.46 & 0.68 & 0.678 & 0.0018 \\
\hline
\end{tabular}




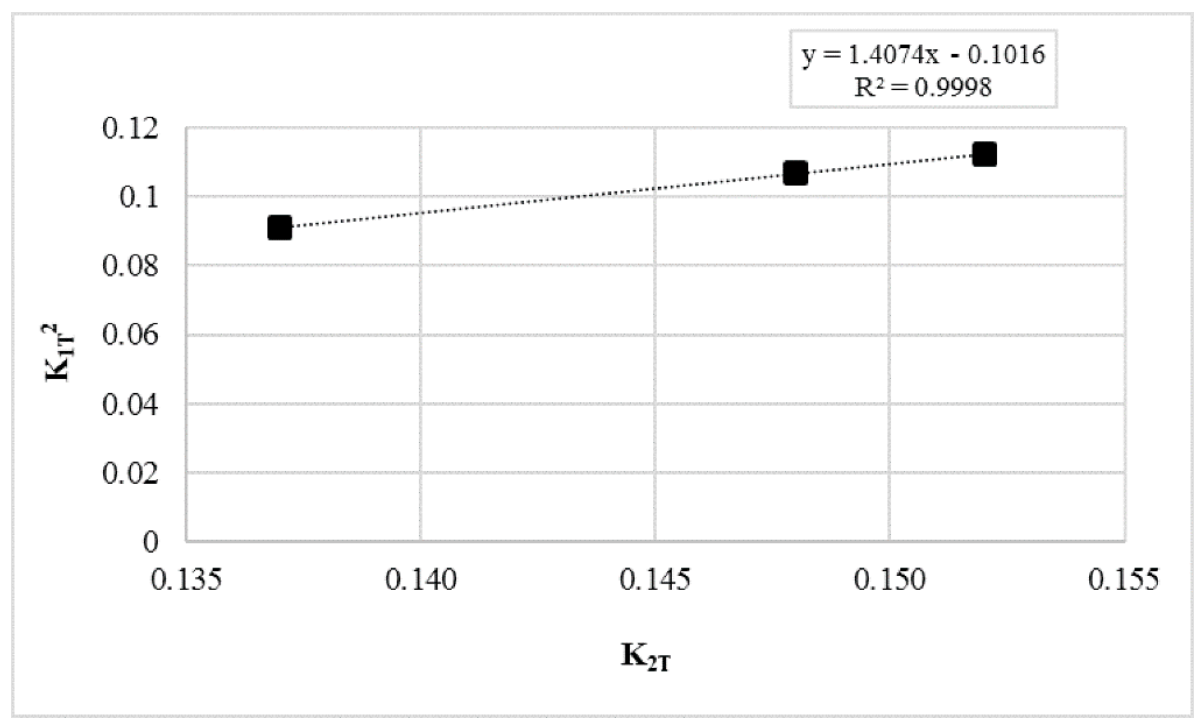

Figure 5. Correlation between $K_{2 T}$ and $K_{1 T}^{2}$.

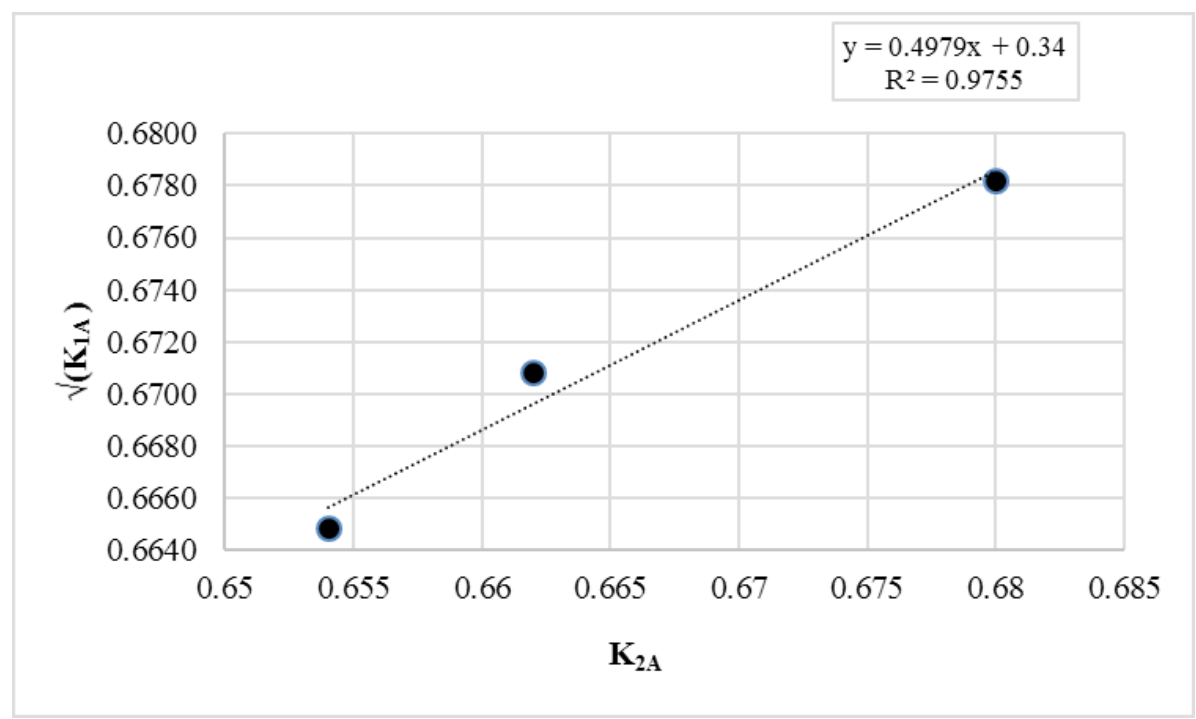

Figure 6. Correlation between $K_{2 A}$ and $\sqrt{K_{1 A}}$.

a correlation between them. In Tables 4 and 5 and Figures 5 and 6 , connections between the coefficients $K_{1}$ and $K_{2}$ for transmission and absorption are presented.

\subsection{Model establishment}

Table 5 shows that $K_{2 A}$ - the calculated absorption through two yarns based on direct measurement (Column 3 in Table 5) presents the square root of $K_{1 A}$ (Column 4 in Table 5) since the values calculated by the presented correlation differed about $<1 \%$ (Column 6 in Table 5). In the case of the transmission presented in Table 4, there is also a correlation between $K_{1 T}$ and $K_{2 T}$ in the form of a power function. In this case, we have obtained almost the same differences between the results of the calculations by the power function and the calculations based on the measurements, with almost a constant difference of about $4 \%$. This coincides with the $\sim 3 \%$ difference in reflection of the one-yarn area and two-yarn area between the samples. All these observations gave us the idea to use the recognized correlations for establishing a simplified model for predicting the UV-protective properties of woven fabrics. Accordingly, we have set the next Equations (12-15):

$$
\mathrm{R}=\mathrm{Cf}_{1} \times \mathrm{K}_{1 \mathrm{R}}+\mathrm{Cf}_{2} \times \mathrm{K}_{2 \mathrm{R}} \text {. }
$$

For simplifying the calculations, because of the small differences between the reflections from one and two yarns, we next modified Equation (12) as follows:

$$
\begin{aligned}
& \mathrm{R}=\mathrm{Cf} \times \mathrm{K}_{\mathrm{R}(\text { average })} ; \\
& \mathrm{T}=\mathrm{Op}+\mathrm{Cf}_{1} \times \mathrm{K}_{1 \mathrm{~T}}+\mathrm{Cf}_{2} \times K_{1 T}^{2} ; \\
& \mathrm{A}=\mathrm{Cf}_{1} \times \mathrm{K}_{1 \mathrm{~A}}+\mathrm{Cf}_{2} \times \sqrt{K_{1 A}} .
\end{aligned}
$$

\subsection{Justifying the model}

For justifying the established model, we have used the data presented in Table 6 and Equations (13-15) to calculate the predicted transmission, reflection, and absorption of selected monofilament materials (e.g., fabrics). 
Table 6. Data used for calculating predicted transmission, reflection, and absorption of the samples

\begin{tabular}{|c|c|c|c|c|c|c|c|}
\hline Sample & Op [\%] & $\mathrm{Cf}_{1}[\%]$ & $\mathrm{Cf}_{2}[\%]$ & Cf [\%] & ${ }^{*} \mathrm{~K}_{\mathrm{R} \text { (average) }}$ & ${ }^{*} K_{1 \mathrm{~T}(1-4) \text { average }}$ & ${ }^{*} K_{1 A(1-4)}$ average \\
\hline 1 & 35.24 & 48.24 & 16.52 & 64.76 & \multirow{8}{*}{0.223} & \multirow{8}{*}{0.335} & \multirow{8}{*}{0.442} \\
\hline 2 & 25.68 & 49.99 & 24.33 & 74.32 & & & \\
\hline 3 & 20.54 & 49.56 & 29.90 & 79.46 & & & \\
\hline 4 & 13.87 & 46.75 & 39.38 & 86.13 & & & \\
\hline 5 & 14.01 & 46.84 & 39.15 & 85.99 & & & \\
\hline 6 & 11.18 & 44.52 & 44.30 & 88.82 & & & \\
\hline 7 & 27.34 & 49.90 & 22.76 & 72.66 & & & \\
\hline 8 & 20.20 & 49.48 & 30.32 & 79.80 & & & \\
\hline
\end{tabular}

Note: *Average values of $K_{1(T, R, A)}$.

Table 7. Examples of calculated (c) and measured $(\mathrm{m})$ values of transmission $(T)$, reflection $(R)$, and absorption $(A)$, with corresponding correlation coefficients

\begin{tabular}{|c|c|c|c|c|c|c|}
\hline Sample & $\mathrm{T}_{\mathrm{m}}[\%]$ & $\mathrm{T}_{\mathrm{c}}[\%]$ & $\mathbf{R}_{\mathrm{m}}[\%]$ & $\mathbf{R}_{\mathrm{c}}[\%]$ & $\mathbf{A}_{\mathrm{m}}[\%]$ & $\mathbf{A}_{\mathrm{c}}[\%]$ \\
\hline 1 & 54.22 & 53.25 & 13.72 & 14.44 & 32.06 & 32.31 \\
\hline 2 & 45.95 & 45.16 & 16.17 & 16.57 & 37.88 & 38.27 \\
\hline 3 & 41.76 & 40.50 & 16.53 & 17.72 & 41.71 & 41.78 \\
\hline 4 & 35.83 & 33.95 & 18.12 & 19.21 & 46.05 & 46.84 \\
\hline 5 & 36.02 & 34.10 & 18.68 & 19.18 & 45.3 & 46.73 \\
\hline 6 & 33.01 & 31.07 & 18.81 & 19.81 & 48.18 & 49.13 \\
\hline 7 & 47.02 & 46.61 & 15.44 & 16.20 & 37.54 & 37.19 \\
\hline 8 & 39.25 & 40.18 & 17.36 & 17.80 & 43.39 & 42.03 \\
\hline $\begin{array}{l}\text { Correlation } \\
\text { coefficient }\end{array}$ & 0.993 & & 0.986 & & 0.990 & \\
\hline
\end{tabular}

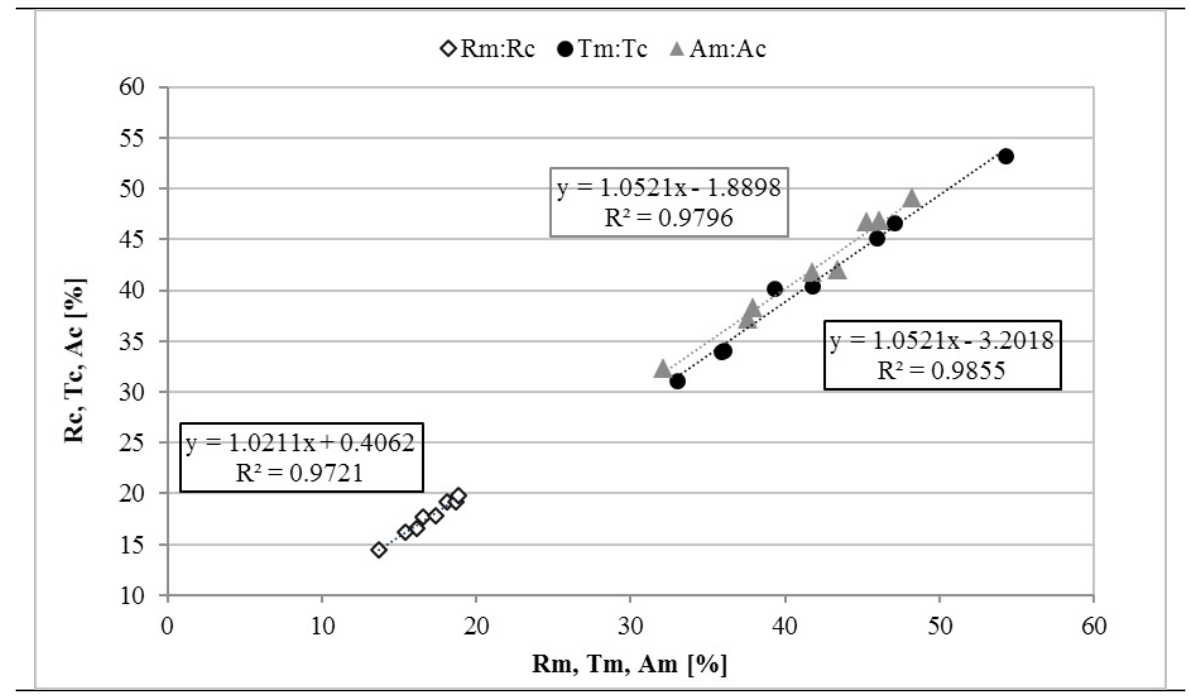

Figure 7. Coefficient of determination between the calculated example and the measured values of sample transmission, reflection, and absorption.

Table 7 presents the calculated values of transmission, reflection, and absorption. Calculations were made using Equations (13-15).
The same results, presented in Figure 7 , clearly show a high degree of correlation between the calculated example predicted and the measured values of transmission, reflection, and absorption of samples. 


\section{CONCLUSIONS}

The presented research shows that the established model for the prediction of the UV-protective properties of the monofilament PET fabrics correlates very well with the real measurements. However, practically, all variables inserted into the equations are not easy to be determined. For that reason, selected monofilament fabrics were chosen, since they enabled precise optical determination of all needed material, e.g., fabric construction parameters of the samples. For the broader use of the model, it must be tested on other types of fabrics, made from different types of yarns. This makes the task more difficult, since constructions of other types of yarns and fabrics allow much more deformation in their structure than monofilament yarns in plain and twill weave. For solving the problem, we suggest two approaches:

Getting the relevant construction parameters of fabrics (Op, $\mathrm{Cf}, \mathrm{Cf}_{1}, \mathrm{Cf}_{2}$ ) through computer-supported image analyses of referential samples [12-14]; and

Indirectly from the measurements of reflection or other permeability properties from the referential samples [15-17].

However, in both cases, the UV-protective properties of used yarns (their $K_{\mathrm{R}}, K_{\mathrm{T}}$ and $K_{\mathrm{A}}$ ) are not known. So, we are working on developing a method, different from the one in the paper by Dimitrovski et al. [5], which can allow easier determination of the mentioned properties of the most used yarns of most interests - cotton yarns, PET, cotton blends, coco, poly(lactic acid) (PLA), soya bean, and so on. Our preliminary research in this field shows that the biggest contribution to the UVprotective properties of yarns comes from the fabric, its color, or any other preparation connected to the chemical structure of the yarns' ingredients. It also seems that the influence of yarn fineness and number of twists (within certain interval), attained in the deformability of yarns, their diameter and density, could be neglected.

As a final conclusion, it can be said that the established model for the prediction of the UV-protective properties of the woven fabrics is very simple, easy to use, and logical, giving promising results. The good thing, in general, is that the calculated prediction is not necessary to be very accurate (meaning, not necessary within $1 \%$ or $2 \%$ ). In this way, the manufacturers of the woven fabrics have plenty of possibilities to plan and arrange the UV-protective properties of fabrics within the desired values.

\section{References}

[1] Urbas, R., Sluga, F., Bartenjev, I. (2004). Influence of constructional parameters on UV protective efficiency of fabrics. Tekstilec, 47, 9-12.

[2] Pezelj, E., Tomljenović, A., Čunko, R. (2004). Textiles for the protection against sun radiation. Tekstil, 53, 301-316.
[3] Dobnik-Dubrovski, P., Golob, D. (2009). Effects of woven fabric construction and color on ultraviolet protection. Textile Research Journal, 79, 351-359.

[4] Gabrijelčič Tomc, H., Urbas, R., Sluga, F., Dimitrovski, K. (2009). Influence of fabric constructional parameters and thread colour on UV radiation protection. Fibres and Textile in Eastern Europe, 17, 46-54.

[5] Dimitrovski, K., Sluga, F., Urbas, R. (2010). Evaluation of the structure of monofilament PET woven fabrics and their protection properties. Textile Research Journal, 11, 10271037.

[6] Gorenšek, M., Sluga, F., Urbas, R. (2007). Improving the ultraviolet protection factor of cotton fabric. AATCC Review, 7(2), 44-48.

[7] Simončič, B., Tomšič, B., Wechtersbach, H., Bračko, S., Radišek, S., et al. (2005). Influence of the components on the efficiency of the multifunctional repellent and antimicrobial finishing with UV protection. Tekstil, 54(1), 1-11.

[8] Bračko, S., Turnšek, N. (2005). Impact of UV-absorbers on UV protective properties and light fastness of coloration of cotton fabric dyed with monofluorine-s-triazine reactive dyes. Tekstil, 54(3), 119-125.

[9] Gorjanc, M., Jazbec K., Mozetič, M., Kert, M. (2014). UV protective properties of cotton fabric treated with plasma, UV absorber and reactive dye. Fibres and Polymers, 15(10), 2095-2104.

[10] Wiener, J., Chládová, A., Shahidi, S., Peterová, L. (2017). Effect of UV irradiation on mechanical and morphological properties of natural and synthetic fabric before and after nano-Tio2 padding. Autex Research Journal, 17(4), 370378.

[11] Pierce, F. T. (1937). The geometry of cloth structure. Journal of the Textile Institute Transactions, 28, 45-96.

[12] Algaba, I., Riva, A., Crews, P. C. (2004). Influence of fiber type and fabric porosity on the ultraviolet protection factor provided by summer fabrics. AATCC Review, 4, 26-31.

[13] Kostajnšek, K., Dimitrovski, K., Hladnik, A. (2013, May). Use of image analysis for the determination of open area fraction in woven fabrics. Proceedings of the 13th Autex Conference, ID 378. Dresden, Germany, 1-6.

[14] Tapias, M., Rallo, M., Escofet, J., Algaba, I., Riva, A. (2010). Objective measure of woven fabrics cover factor by image processing. Textile Research Journal, 80(1), 3544.

[15] Kostajnšek, K., Dimitrovski, K. (2015, June). Fast effective method for predicting UV protective properties of woven fabrics. Proceedings of 15th Autex Conference, ID 199. Bucharest, Romania, 1-6.

[16] Nazir, A., Hussain, T., Afzal, A., Faheem, S., Ibrahim, W., et al. (2017). Prediction and correlation of air permeability and light transmission properties of woven cotton fabrics. Autex Research Journal, 17(1), 61-66.

[17] Kostajnšek, K., Dimitrovski, K. (2013). Multilayer cotton fabrics porosity and its influence on permeability properties. Tekstilec, 56(4), 335-344. 